\title{
The influence of barley weed impurities on the microbiological quality indicators
}

\author{
Elena Belokurova ${ }^{1}$, Ilona Pankina $^{1}$, Anna Sevastyanova ${ }^{1}$, Irina Asfondyarova ${ }^{1}$, and Nina Katkova ${ }^{1}$ \\ ${ }^{1}$ Peter the Great St. Petersburg Polytechnic University, 195251, St. Petersburg, Russia
}

\begin{abstract}
Currently, malting barley is one of the most important crops that form the basis of the food business in the Russian Federation. Malting barley is imported to Europe, Asia, Africa and South America. While storing and transporting grain, its microbiological quality indicators play a very important role. Grain seeded with various microorganisms quickly loses its functional and technological properties, which negatively affects the quality of beer produced from it. According to the results of the studies, it was found that the contamination of barley with microorganisms is greatly influenced by various impurities that enter the grain mass during harvest. As well as various impurities in the grain mass of malting barley, the grains of other plants wheat, rye and oats were found in some samples in quantity of about $4 \%$. There were also a lot of beaten barley grains, in some samples more than $2 \%$. The moisture content of the grain mass also affects the seeding by microorganisms. Impurities had a higher humidity than grain, purified from impurities. To reduce the microbial contamination of brewing barley grains, it is necessary to thoroughly clean and refine the grain mass immediately after harvesting.
\end{abstract}

\section{Introduction}

In the Russian Federation, a large number of grain and leguminous crops is grown. Most of them are used for food and feed purposes. Harvested once a year, the grain should be stored.

Malting barley grain is a complex multicomponent multifunctional biological system, the state of which during storage and transportation is influenced by many environmental factors [1]. The vital activity of grain directly depends on the state of the grain mass: grain moisture, temperature, oxygen saturation. Depending on the elasticity of the water vapor in the surrounding air, the grain may become wet or dry. By virtue of the laws of sorption equilibrium, the grains of other plants, especially weeds, which have different humidity, will change it in accordance with the vapor pressure established in the grain mass. Raw grains might lose some of the moisture, and drier grains will become moisture. A similar redistribution of moisture is seen in the grain mass containing more moist seeds of other plants [2].

A study of the factors affecting the development of saprophytic microorganisms in the grain mass showed that the following factors are critical: the average moisture content of the grain mass, the moisture content of individual components of the grain mass (humidity of the main grain, impurities and air of intergranular spaces), the temperature of the grain mass and the degree of aeration. The integrity and condition of the integumentary grain tissues, its vital functions, the amount and species composition of impurities are also essential [3].

If the moisture content of the grain mass of any culture is significantly higher than critical, then in the presence of other favorable conditions (mainly a certain temperature), microorganisms develop rapidly, which is accompanied by noticeable changes in the quality of the grain. The intensity of the process is explained by the presence in the microcapillaries of the shells of the grain of a significant amount of water used by microorganisms [4].

Thus, humidity is one of the important indicators of quality, which affects the preservation of the functional and technological properties of malting barley during storage.

The boundary of the appearance of free water in the grain, at which a sharp increase in the intensity of respiratory processes is observed, is called critical humidity. Its value depends on the type of grain, the anatomical structure and chemical composition. The more starch and protein the grain contains, the higher the critical humidity. It is low for oilseeds, because the water in them is retained only by the non-lipid part of the seeds (table 1).

\footnotetext{
* Corresponding author: Makarovayulia169@mail.ru
} 
Table 1. The critical humidity of grains and seeds of cereals and legumes.

\begin{tabular}{|l|c|}
\hline \multicolumn{1}{|c|}{ Name of crops } & $\begin{array}{c}\text { The value of } \\
\text { critical humidity, } \\
\text { \% }\end{array}$ \\
\hline Wheat, rye, barley, oats, buckwheat & $14.5-15.5$ \\
\hline Peas, lentils, chickpeas, beans & $15.0-16.0$ \\
\hline Corn & $13.0-14.0$ \\
\hline Millet & $12.0-13.0$ \\
\hline
\end{tabular}

Grains and seeds of cereals and legumes that contain free water in a value below critical are considered dry and suitable for storage.

The purpose of this study: to establish the relationship between the moisture content of various fractions of the grain mass of malting barley and its microbiological contamination.

\section{Research methods}

At first, a study was conducted of malting barley on the content of impurities in it and on the determination of mass fraction of moisture. To check the conformity of the quality of malting barley grain to the requirements of regulatory and technical documentation, we analyzed the average sample weighing $2.0 \pm 0.1 \mathrm{~kg}$, isolated from the combined grain sample.

In accordance with the regulatory and technical documentation in the Russian Federation in malting barley intended for food purposes, impurities are divided into two groups: weed and grain.

The division of impurities into the indicated groups is based on their unequal effect on the consumer advantages of grain, on its safety and the quality of goods produced from a given batch of grain.

Weed impurity includes such components of the grain mass that sharply aggravate the consumer characteristics of the grain and cannot be applied for a reasoned purpose together with the grain of the main crop. They usually also reduce the shelf life of grain [5].

The determination of contamination from the average sample of malting barley was carried out manually, grain sample (100 g) was isolated by squaring.

A portion of the grain was sieved on laboratory sieves, using sieves with oblong or round holes.

The sieves were installed in the following order: 1. pallet;

2. a sieve with holes with a diameter of $1.5 \mathrm{~mm}-$ to isolate weed impurities;

3. a sieve with holes $2.2 \times 20 \mathrm{~mm}$ in size - to isolate small grains;

4. a sieve with holes $2.5 \times 20 \mathrm{~mm}$ in size - to isolate large grains [6].

Sifting the test sample of grain on a set of sieves, a variational series of grain variability by size and contamination was obtained within a few minutes. At the same time, sieve analysis allows us to determine the variability of grain by thickness and width. It should be noted that grains coming from different sieves also have different weights, that is, there is a certain relationship between the indicators of linear sizes and the weight of the grain - larger grains have larger weight.

Using sieve analysis methods, it is possible to choose the correct methods for cleaning grain from impurities that provide the greatest technological effect. To find out the possibility of separating weeds from the grain, it is necessary to obtain variational curves of the length, thickness and width of both the main crop and impurities. If the curves of the variational series, constructed by any criterion, do not overlap, then a complete separation of the components of this mixture by this criterion is possible. If one variation curve overlaps another, then separation by this attribute is impossible and it is necessary to look for other cleaning methods [7].

The moisture content in various fractions of the grain mass was also determined. The determination was carried out by the accelerated method of drying the crushed portion of malting barley at $130^{\circ} \mathrm{C}$.

After determining the moisture, QMAFAnM (Quantity of Mesophilic Aerobic and Facultative Anaerobic Microorganisms) malting barley was determined. The determination of the quantity of mesophilic aerobic and facultative anaerobic microorganisms was carried out by the standard method of sowing a diluted portion of malting barley in Petri dishes with nutrient agar, incubating for 48 hours, then counting all grown visible colonies.

According to the experimental design, the following samples were taken to determine QMAFAnM:

-unpeeled and unsorted barley;

-peeled and unsorted barley;

-peeled and sorted barley.

To conduct an experiment to determine QMAFAnM, the titer method (limit dilution method) was used. The order of operations in the experiment: a sample of malting barley was crushed under sterile conditions, in parallel, a series of tubes with $9 \mathrm{ml}$ of sterile saline was prepared. $1 \mathrm{~g}$ of ground malting barley was placed in the first test tube, everything was mixed, then $1 \mathrm{~cm} 3$ from the first test tube was added to the second test tube and mixed again, then $1 \mathrm{~cm} 3$ from the second test tube was added to the third test tube, and so on. Then, $1 \mathrm{~cm} 3$ of the 2 nd, 3rd, and 4th dilutions were sown in two parallel Petri dishes with nutrient agar.

Colonies of microorganisms were incubated at a temperature of $(35 \pm 1){ }^{\circ} \mathrm{C}$ for $(48 \pm 2) \mathrm{h}$. After incubation the number of colonies grown on Petri dishes was counted. Colonies of microorganisms were counted using a magnifier, giving a $5 \mathrm{x}$ zoom, i.e., small, point colonies were also taken into account.

The method for determining the amount of yeast and mold in malting barley is based on sowing diluted ground grain on Sabouraud agar. Dilution was prepared by the method of titer (method of limiting dilutions).

The basis of Sabouraud agar was prepared as follows: 40.0 glucose, $10.0 \mathrm{~g}$ peptone, $18.0 \mathrm{~g}$ agar were added to $1 \mathrm{dm} 3$ of distilled water. The mixture was heated, stirring occasionally, until the components melted, cooled to $45-55^{\circ} \mathrm{C}$, adjusted to $\mathrm{pH}$ so that after sterilization it was $6.5 \pm 0.1$ at $25^{\circ} \mathrm{C}$, poured into volumetric flasks and sterilized for $15 \mathrm{~min}$ at 
temperature $(121 \pm 1)^{\circ} \mathrm{C}$. The basis of the medium was stored at a temperature of $(4 \pm 2){ }^{\circ} \mathrm{C}$ for no more than 14 days.

During the experiment, $1 \mathrm{~cm} 3$ of the 2 nd and $3 \mathrm{rd}$ dilutions were sown on Sabouraud agar and incubated in an incubator at $(30 \pm 1)^{\circ} \mathrm{C}$ for $(72 \pm 3)$ hours.

After cultivation, the grown colonies of microorganisms were counted. To separate the colonies of yeast and molds, microscopic studies were carried out. For this purpose, preparations were done from separate colonies by the method of "crushed drop". A drop of sterile tap water was applied to a glass slide. Then, part of the colony was embedded into this drop of a calcined bacteriological loop. The resulting suspension was covered with a coverslip and studied under a microscope with a magnification of 120 or 600 times.

\section{Results and its discussion}

The results of determining the contamination of the studied samples of malting barley by mechanical separation of it into fractions are shown in fig. 1.

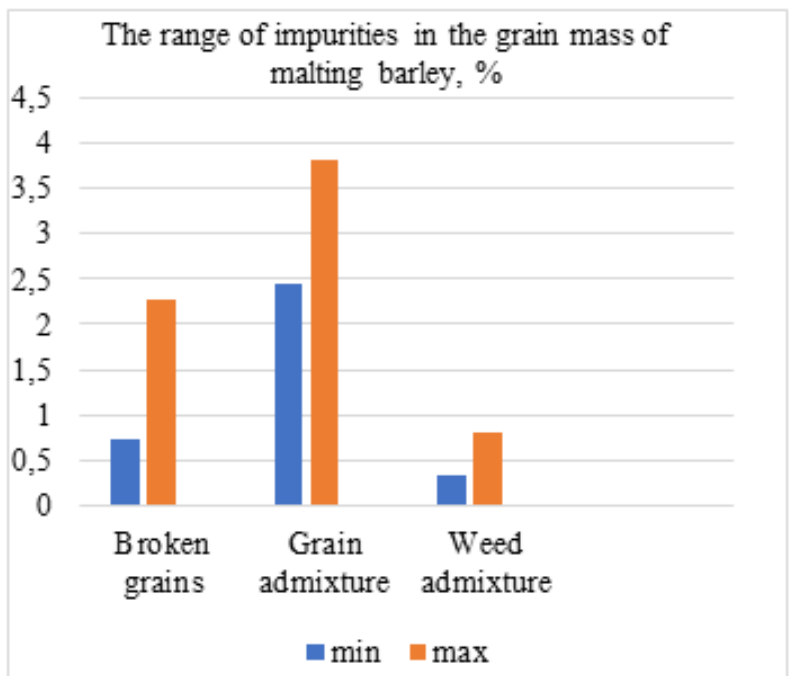

Fig. 1. The range of impurities in the grain mass of malting barley.

Analysis of figure 1 shows an increased content of grain impurities, as in accordance with the requirements of regulatory and technical documentation should be no more than $2.0 \%$.

The grain impurities of malting barley include whole and damaged grains of other plants: wheat, spelled, rye and oats.

As well as grain impurities include grains of malting barley:

-eaten by pests, regardless of the nature and size of the damage;

-unripe: severely underdeveloped - feeble, as well as green deforming when pressed with a spatula; -sprouted - with a spine or sprout coming out; -damaged by self-heating or drying, with a changed shell color and endosperm from cream to light brown.
Beaten grains of the main culture (barley) were separated from the whole mass of grain impurities, because they can be used for feed purposes.

The results of determining the moisture content of various fractions of malting barley are presented in table 2 .

Table 2. Moisture content in different fractions of the grain mass of malting barley, $\%$.

\begin{tabular}{|c|c|c|c|}
\hline $\begin{array}{c}\text { Name of } \\
\text { samples }\end{array}$ & $\begin{array}{c}\text { Barley grain, } \\
\text { purified } \\
\text { from } \\
\text { impurities }\end{array}$ & Impurities & $\begin{array}{c}\text { Barley grain } \\
\text { with } \\
\text { impurities }\end{array}$ \\
\hline Sample № 1 & 14.5 & 18.0 & 16.0 \\
\hline Sample № 2 & 15.5 & 19.1 & 16.8 \\
\hline Sample № 3 & 15.0 & 18.6 & 16.5 \\
\hline Sample № 4 & 14.5 & 17.9 & 15.9 \\
\hline
\end{tabular}

The analysis of table 2 shows that the impurities have an increased humidity compared with the purified grain of malting barley.

Grains of barley with broken shell, beaten and crushed barley grains are hygroscopic and absorb moisture well. Having high humidity, impurities are the main focus of the development of microorganisms, therefore, after harvesting, it is necessary to carry out post-harvest cleaning of impurities.

The critical humidity of malting barley grain is 14.5 $15.5 \%$. Malting barley grain containing free water below a critical value is considered dry and suitable for storage.

Studies conducted by K. N. Danovich and other scientists who research the state of water in the seeds of cereal crops showed the presence of a number of water fractions with specific physicochemical parameters and types of interaction with various structures and biochemical substances of the seed. At the same time, 4 fractions of water were isolated in grains:

-the first fraction - protein hydrated water; -the second - water hydrating reserve polysaccharides; -the third - water immobilized by structural proteins; -the fourth - water in the liquid fraction (similar to free, clean water) [8].

A study of the effect of individual water fractions on the preservation of grains showed that the content of the second fraction (starch-hydrated complex) of water positively correlates with the preservation of grains. Grain seeds containing a significant amount of storage carbohydrates, mainly starch, have a high preservation compared to seeds of other species, apparently due to the buffer role of starch [9].

The third water fraction, concentrated mainly in the germinal part of the grain, is resistant to physical influences, and its loss with barley grain would have a catastrophic effect on the vital processes occurring in the embryo. The moisture of the embryo, presumably, is one of the sides of the protection mechanism most important in reproducing the type of part of the grain - the embryo - from the influence of adverse environmental factors. With increasing humidity, barley grains come out of a state of forced rest, they are able to germinate [10].

In wet years, harvesting by agreement of the procuring organization and the supplier, grain moisture 
and the content of weed impurities in the procured barley are allowed to be more restrictive if it is possible to bring such grain to conditions ensuring its safety.

According to the results of our research, cleaning grain from impurities reduces the moisture content of the grain mass and brings it to standard.

The results of the determination of QMAFAnM are presented in fig. 2 .

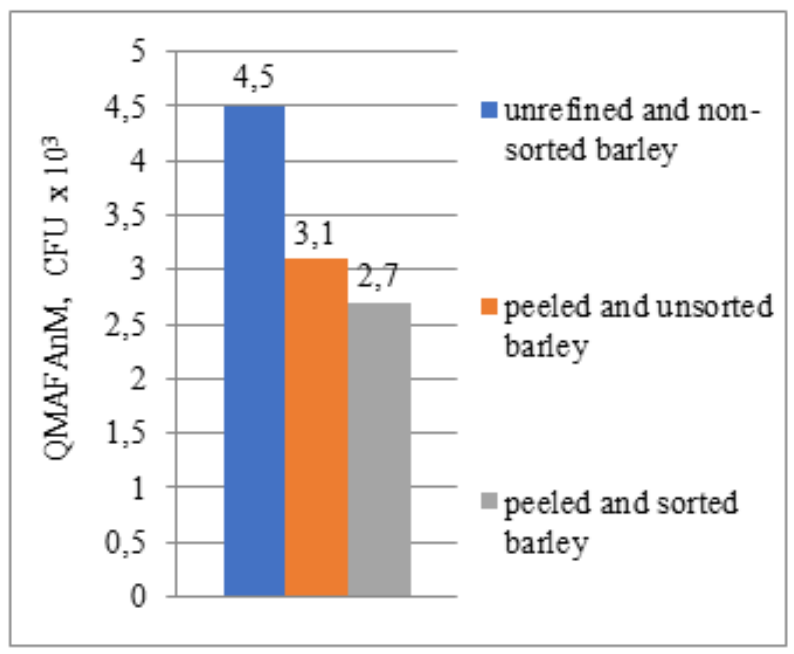

Fig. 2. Microbiological contamination of the studied samples of malting barley.

Most of the grown colonies of microorganisms were yellow stained. A study of the cultural and morphological properties of the grown colonies of microorganisms showed that rod-shaped bacteria predominate in the studied grain mass of malting barley and there are coccal forms.

A comparative analysis of the data presented in fig. 2 shows that unrefined and unsorted malting barley is infected with microorganisms 1.6 times more than peeled and sorted barley.

In our case, this can be explained by a large number of damaged grains. It often occurs when harvesting due to an incorrectly selected harvesting time and threshing mode. Malting grain damages increases even more when processing and transporting grain to storage. Microorganisms easily penetrate into the grain through microdamage of integumentary tissues, therefore the grain mass with a large number of damaged grains is very heavily infected with microorganisms [11].

The results of determining the content of yeast and molds are presented in fig. 3 .

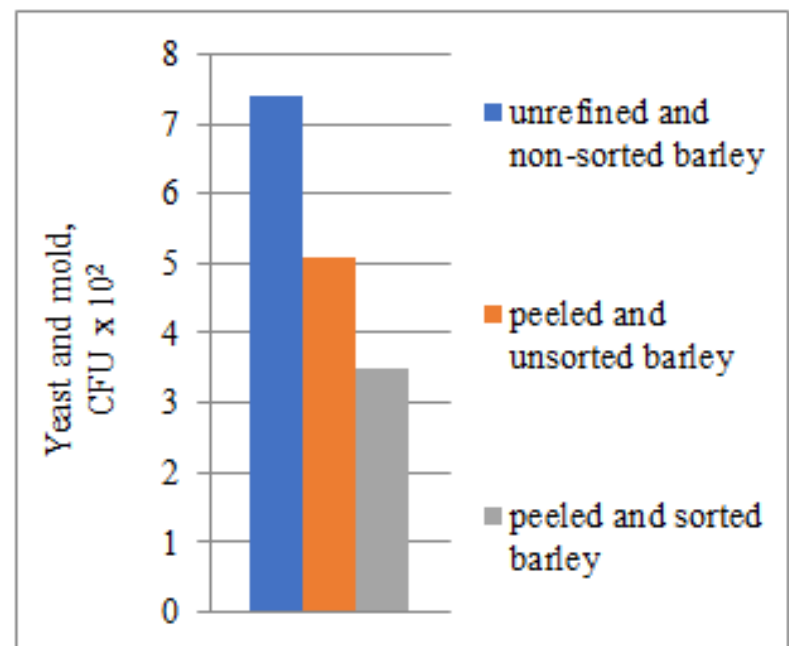

Fig. 3. The content of yeast and mold in the studied samples of malting barley.

The results of determining the content of yeast and mold shows a direct relationship between the number of micromycetes and the degree of purification of barley. Barley sorting also affects the content of yeast and mycelial fungi [12].

A comparative analysis of fig. 2 and 3 shows that in the samples of purified and sorted malting barley, the proportion of yeast and molds is about a tenth of the total number of microorganisms, and in samples of untreated and unsorted barley, yeast and molds make up one fifth of the total number of microorganisms. This suggests that impurities, as well as damaged grains, are much more contaminated by yeast and mold spores than whole grains.

Nowadays there are innovative methods providing higher quality, increasing the shelf life of products and being potentially able to provide better preservation. The use of ionizing radiation is currently permitted in many countries to reduce microbial contamination of grain and reduction of losses during storage of barley. Bacteriocins are widely using in processing grain [13-15].

\section{Conclusion}

Immediately after harvesting, the grain mass of malting barley consists of:

- $\quad$ malting barley grains of various state and quality;

- $\quad$ grains of other cultivated plants;

- all kinds of mineral and organic impurities.

In the technology of postharvest treatment and storage of malting barley, more attention should be paid to the composition of the grain mass: the less impurities, the higher quality of grain. The presence of a large amount of grain impurities indicates a low level of purification of the collected malting grain, therefore, it is necessary to carry out measures to replace the grain cleaning equipment at the procurement enterprises or to additionally refine the malting grain to reduce the amount of impurities and give the grain a "marketable condition".

Upon receipt of malting barley above the restrictive norms for moisture content, it must be brought to the 
basic norm by drying. For these purposes there must be appropriate equipment. Otherwise, the malting grain will be poorly stored. This condition is especially important to follow in rainy years.

A direct proportional relationship is observed between the content of impurities and the moisture content of the grain mass: the more impurities, the higher the moisture content of the malting barley grain.

QMAFAnM of malting barley depends on the degree of purification and the quality of barley sorting. The smallest microorganisms were found in a refined and sorted sample of malting barley.

The content of yeast and mold also correlates with the amount of impurities in the grain mass.

In order to improve microbiological indicators of the quality of malting barley, which affect the shelf life, it is necessary to carry out high-quality side work of the grain mass and its sorting even before putting it for storage.

\section{References}

[1] V.L. Pilipyuk, Grain and seed storage technology, M.: High school textbook (2009).

[2] N.M. Lichko (Ed.), Technology for processing crop products, M .: KolosS (2008).

[3] T. Öztürk, B. Esen, Physical and Mechanical Properties of Barley, Agricultura Tropica Et Subtropica, 41, 3 (2008).

[4] T.P. Lapina, Beer and drinks, 5 (2001).

[5] E.N. Efremova, Bulletin of the Agrarian University of Northern Zauralye, 1, 32 (2016).

[6] S.Ya. Koryachkina, N.V. Labutina, N.A. Berezinai, et al., Quality control of raw materials, semi-finished products and bakery products: Textbook for universities, M.: DeLi Plus (2012).

[7] A.F. Druzhkin, Yu.V. Lobachev, L.P. Shevtsova, Z.D. Lyashenko, Fundamentals of scientific research in crop production and selection: Textbook, Saratov: Saratov State Agrarian University (2013).

[8] E.D. Kazakov, G.P. Karpilenko, Biochemistry of grain and bakery products, St. Petersburg: GIORD (2005).

[9] R.K. Hosni, Grain and grain products. M: Profession (2006).

[10] L.N. Narcissus, Malt production technology, St. Petersburg: Profession (2007).

[11] G.G. Yusupova, Bakery of Russia, 2 (2007).

[12] N.V. Tsuglenok, G.I. Tsuglenok, G.G. Yusupova, An integrated system for the disinfection of grain and products of its processing, Krasnoyarsk: Krasnodar State Agrarian University (2004).

[13] I.A. Pankina, E.S. Belokurova, N.A. Politaeva, V.N. Lomasov, N.Z. Bashun, E3S Web of Conferences: International Science Conference on Business Technologies for Sustainable Urban Development, SPbWOSCE 2018, St. Petersburg: EDP Sciences (2019).

[14] T. Abi, L. Crokel, S. Hill, International Journal of Food Microbiology, 28 (1995).
[15] T. Pilipenko, E. Belokurova, I. Pankina, A. Shlykova, IOP Conference Series: Earth and Environmental Science (2019). 